\title{
Development of Targeted Therapies in ErbB2-Positive Breast Cancer
}

\author{
Christian Jackisch $^{\mathrm{a}}$ Josef Rüschoff ${ }^{\mathrm{b}}$ Axel Ullrich ${ }^{\mathrm{c}}$ \\ a Department of Obstetrics and Gynecology and Breast Cancer Center, Klinikum Offenbach GmbH, \\ bPathologie Nordhessen and targos molecular pathology $\mathrm{GmbH}$, Kassel \\ ${ }^{c}$ Max-Planck-Institut für Biochemie, Martinsried, Germany
}

\section{Identification of ErbB2 (HER2) as Treatment Target}

The traditional view of breast cancer as a single-tumor entity has been challenged in recent years. Today, breast cancer is considered a heterogeneous group of different carcinomas, one of them being the ErbB2-overexpressing breast tumor. The adverse prognosis of women with ErbB2-overexpressing breast cancer and the correlation of survival and relapse rates with the number of ErbB2 gene copies were described 20 years ago by Slamon et al. [1]. The monoclonal antibody trastuzumab was the first agent targeting the ErbB2 signaling pathway and received FDA approval in 1998. The molecular characterization of ErbB2-overexpressing breast cancer and the development of trastuzumab were made possible by the identification of a new receptor with extensive homology to the epidermal growth factor receptor (EGFR), which was, therefore, named Human EGFR-Related Receptor (HER2) [2]. It could also be demonstrated that HER2 shares the same gene locus as the neu oncogene identified in tumors of the rat [2-5].

\section{Development of Anti-ErbB2 Therapy}

Trastuzumab was initially investigated as a single agent in the therapy of metastatic breast cancer, and was shown to be generally safe and to produce response rates in the range of $12-35 \%$ [6]. These first results were somewhat disappointing, but they probably reflect the fact that cancer is not a monogenic disease linked to only one molecular alteration. Therefore, multimodality treatment approaches and multi-targeted agents are needed for better treatment outcome.

The combination of trastuzumab with anthracycline/cyclophosphamide or paclitaxel provided additional benefit with higher rates of response and survival. The pivotal trial by Slamon et al. [7] showed for the first time a significant survival advantage in metastatic breast cancer by combining chemotherapy with a targeted agent. This trial and others also revealed that the benefit of trastuzumab is limited to women with breast cancers strongly overexpressing ErbB2 (immunohistochemistry (IHC) $2+$ or $3+$; fluorescent in situ hybridization $(\mathrm{FISH})+)$. On the other hand, researchers and clinicians had to learn about the cardiotoxicity of the antibody, especially in women treated with anthracyclines or presenting with cardiovascular comorbidities.

Having established the principal efficacy of the trastuzumabbased therapy, newer studies addressed the issue of optimizing the anti-ErbB2 therapy. In a randomized phase II trial, Marty et al. [8] demonstrated a significant survival benefit for patients receiving a combination therapy with docetaxel and trastuzumab, compared to women who were treated with docetaxel only and received trastuzumab after progression $(p=0.0325)$. This result underlines the basic principle in antitumor therapy: to use the most effective drugs as early in the course of the disease as possible. Apart from anthracyclines and taxanes, many other combinations of chemotherapy and trastuzumab have been clinically tested, based on preclinical evidence of synergistic or additive activity, when combining the monoclonal antibody with cytotoxics such as vinorelbine or cisplatin [8].

Optimal duration of trastuzumab therapy remains an unanswered question. It is widespread clinical practice to continue the monoclonal antibody with second-line chemotherapy after progression, although the benefit of this strategy has never been established in a prospective randomized clinical trial. Based on a treatment extension trial $(\mathrm{H} 0659 \mathrm{~g})$ by Tripathy et al. [9] and experience from retrospective analyses, the safety of giving trastuzumab beyond progression can be assumed [9-11]. The trial Treatment Beyond Progression, initiated by the German Breast Group, which compares capecitabine as monotherapy versus capecitabine plus trastuzumab continuation in patients with metastatic ErbB2-overexpressing breast cancer,

\begin{tabular}{|c|c|}
\hline KARGER & (c) 2008 S. Karger GmbH, Freiburg \\
\hline $\begin{array}{l}\text { Fax +49 } 7614520714 \\
\text { E-mail Information@Karger.de } \\
\text { www.karger.com }\end{array}$ & $\begin{array}{l}\text { Accessible online at: } \\
\text { www.karger.com/brc }\end{array}$ \\
\hline
\end{tabular}

Prof. Dr. med. Christian Jackisch

Klinik für Gynäkologie und Geburtshilfe und Brustzentrum Klinikum Offenbach $\mathrm{GmbH}$

Starkenburgring 66, 63069 Offenbach, Germany

Tel. +49 69 8405-3850, Fax -4456

E-mail christian.jackisch@klinikum-offenbach.de 
Table 1. Many patients (40-50\%) do not respond to combination therapies with trastuzumab plus chemotherapy $[6,7]$
Table 2. The majority of responders to trastuzumab plus taxane or vinorelbine will progress within 1 year of therapy

\begin{tabular}{lllll}
\hline Trial & Patients, $n$ & $\begin{array}{l}\text { Line of } \\
\text { treatment }\end{array}$ & Treatment & ORR, \% \\
\hline M77001; Marty et al. 2005 [8] & 92 & $\begin{array}{l}\text { 1st } \\
\text { 1st }\end{array}$ & $\begin{array}{l}\text { T + D vs. D } \\
\text { T + P vs. P }\end{array}$ & $\begin{array}{l}61 \\
49^{\mathrm{b}}\end{array}$ \\
\hline
\end{tabular}

a183 of 188 patients had received prior adjuvant chemotherapy and received first-line $\mathrm{T}+\mathrm{P}$ for $\mathrm{MBC}$. ${ }^{b}$ Smith 2001 [23]; Data are for subgroup of patients with ErbB2 IHC 3+ and treated with T + P. $\mathrm{MBC}=$ Metastatic breast cancer; $\mathrm{ORR}=$ overall response rate (complete or partial response); $\mathrm{P}=$ paclitaxel; $\mathrm{T}=$ trastuzumab $; \mathrm{D}=$ docetaxel.

\begin{tabular}{|c|c|c|c|}
\hline Trial & Line of treatment & Treatment & $\begin{array}{l}\text { Median duration } \\
\text { of response, months }\end{array}$ \\
\hline M77001; Marty et al. 2005 [8] & $1 \mathrm{st}$ & $\mathrm{T}+\mathrm{D}$ vs. $\mathrm{D}$ & 11.7 \\
\hline $\begin{array}{l}\text { H0648g; Slamon et al. } 2001[7]^{\mathrm{a}} \\
\text { Smith } 2001[23]\end{array}$ & $1 \mathrm{st}$ & $\mathrm{T}+\mathrm{P}$ & $10.9^{\mathrm{b}}$ \\
\hline Burnstein et al. 2001 [14] & 1 st or $2 \mathrm{nd} / 3 \mathrm{rd}$ & $\mathrm{T}+\mathrm{V}$ & 5.5 \\
\hline
\end{tabular}

aPaclitaxel subgroup from H0648g; 183 of 188 patients had received prior adjuvant chemotherapy and received first-line $\mathrm{T}+\mathrm{P}$ for $\mathrm{MBC}$.

${ }^{\mathrm{b}}$ Smith 2001 [23]; data are for subgroup of patients with ErbB2 IHC 3+ and treated with T $+\mathrm{P}$. $\mathrm{P}=$ Paclitaxel $; \mathrm{T}$ = trastuzumab; $\mathrm{D}=$ docetaxel $; \mathrm{V}=$ vinorelbine. who progressed during trastuzumab treatment, did not reach its recruitment goal and was terminated prematurely [12].

\section{Potential Drawbacks of Single-Targeted Therapy}

Despite the high activity of combination therapies with trastuzumab and cytotoxic drugs, a substantial proportion of patients with ErbB2-overexpressing breast cancer will not benefit. In the first-line setting, only $50-60 \%$ of patients will respond to regimens with trastuzumab and a taxane (table 1) [6, 7]. The inhibition of only one target of the ErbB family does not appear to be sufficient, in part because of the redundancy in ErbB-mediated intracellular downstream signaling. In addition, response duration in responders to trastuzumab plus a taxane or vinorelbine is limited (table 2): The majority of patients will progress within a year after therapy initiation $[6,7$, 13]. Long-lasting control of the metastatic disease or even cure is not within reach. With better control of the systemic disease and longer survival times, the increasing incidence of central nervous system (CNS) disease also represents a growing challenge which cannot be addressed with trastuzumab.

It is evident that there still is a significant unmet medical need for trastuzumab-pretreated patients with ErbB2-overexpressing breast tumors. Novel anti-ErbB2 therapies, such as the ErbB tyrosine kinase inhibitors which act through different mechanisms, could provide additional benefit in treating women with this type of breast cancer.

\section{From Single-Target to Multi-Target Agents}

In the early development of small molecules inhibiting receptor tyrosine kinases, the effort was focused on creating very selective agents targeting only one specific molecule. Examples are erlotinib and gefitinib which were designed to block the tyrosine kinase of EGFR, thereby interfering with the signal transduction initiated by this receptor. But there is growing evidence that these single-targeted inhibitors are less specific than initially thought and presumably block several receptor kinases. As the different signaling pathways form a complex and partially overlapping intracellular network, it appears to be more appropriate to develop multi-targeted tyrosine kinase inhibitors which are able to modulate several signal transduction pathways. Examples for these multi-targeted agents are sunitinib, which blocks many different kinases including vascular endothelial growth factor (VEGF) and platelet-derived growth factor (PDGF) receptors and thereby angiogenesis, tumor cell proliferation, and metastatic properties, and lapatinib which inhibits ErbB1 and ErbB2. Moreover, it was demonstrated in vitro that these drugs are even less specific: For example, sunitinib has been shown to inhibit about $130 \mathrm{ki}-$ nases. Future anti-cancer therapies should use combinations of several tyrosine kinase inhibitors with different targets, e.g. in the EGFR and VEGFR signaling pathways, in order to maximize the effects against tumor cells with their highly activated signal transduction systems. 


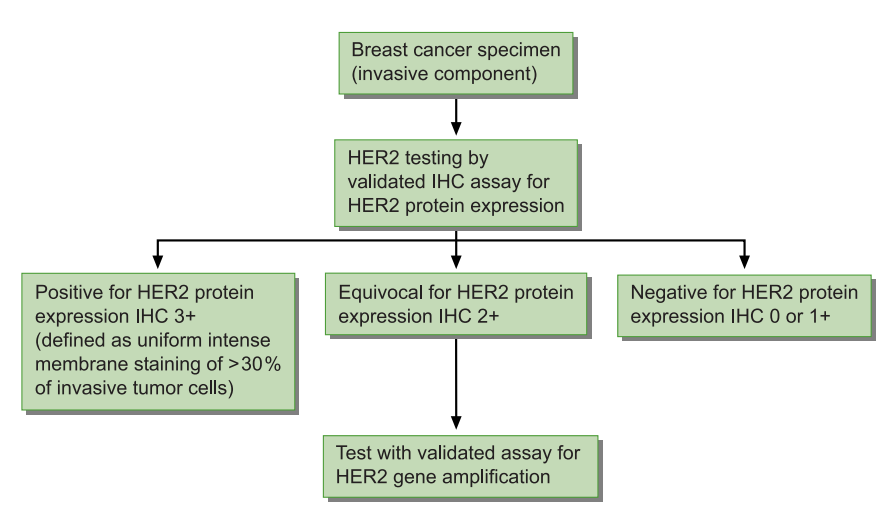

Fig. 1. ASCO/CAP recommendations for ErbB2 testing, adapted from [18].

\section{Methods of Measuring ErbB2-Overexpression}

Presumably, the clinical application of modern targeted agents can help to individualize the therapy of cancer patients by tailoring treatment to tumors defined by the specific target. This requires the development of methods to identify the molecular target in tumors and biopsies. Besides hormone receptors, ErbB2 has proven its value in predicting clinical sensitivity to a targeted therapy in breast cancer.

Routinely, the ErbB2 status of breast cancer patients is assessed by 2 methods: By IHC, the expression of the receptor protein in the cell membrane is estimated by a score ranging from 0 to 3. An IHC value of $3+$ represents ErbB2 overexpression and has been defined as an indication for the initiation of an anti-ErbB2 therapy. By contrast, an IHC score of 2+ is more difficult to interpret and needs validation by FISH, a method which quantifies gene amplification. There has been much discussion about which method being the optimal one for treatment decisions. Advantages of the IHC are its broad availability in nearly every pathological lab, the simplicity of the method and low costs. In comparison to FISH data, $8-22 \%$ of measurements have been called false negative, and up to $40 \%$ false positive [14]. The reproducibility of local IHC3+ test results by central testing normally lies in the range of $76-84 \%$ with values close to FISH data if standardized test systems and the same tissue block have been used for both methods $(81.6 \%$ in IHC versus $88.6 \%$ for FISH) [15]. By contrast, FISH has a high reliability and the results are more reproducible so that FISH was claimed to be the gold standard in ErbB2 testing [16]. Disadvantages of this method are high costs and the availability in specialized labs only. In general, IHC $3+$ tumors also stain pos- itive in the FISH analysis. The variability of IHC results can be explained by the missing standardization of methods of tissue sampling and fixation, and by the utilization of different assays. Another issue is the heterogeneity within the tumor tissue with ErbB2-overexpressing (IHC 3+) cell clones and only weakly to moderately stained clones (IHC $2+$ ) found closely together. This is also relevant for FISH testing, as focal tumor cell clones with different degrees of ErbB2 amplification have been described [17]. A focal distribution of different cell clones is a rare phenomenon and demonstrated in only $1 \%$ of cases. By contrast, an inhomogenous distribution can be found in approximately $15 \%$ of specimens.

The American Society of Clinical Oncology (ASCO) and the College of American Pathologists (CAP) have recently published updated guideline recommendations concerning ErbB2 testing [18]. The expert panel strongly recommends ErbB2 testing in all invasive breast tumors primarily by IHC. A FISH validation is not necessary for breast cancer specimens with a strong IHC3+ expression, defined as a uniform and intense membrane staining of more than $30 \%$ of invasive tumor cells. By contrast, in cases with less than $30 \%$ of cells with intense membrane staining and in specimens with moderate staining (IHC2+) validation by FISH is required (fig. 1).

It has to be kept in mind that FISH assays can also give intermediate results which were defined by ASCO and CAP as HER2/CEP17 ratios ranging from 1.8 to 2.2. Nevertheless, such specimens can show a strong IHC3+ expression, probably due to polysomy 17 which is observed in about $8 \%$ of all breast cancer specimens $[19,20]$. At least some of these cases are responders to trastuzumab [21]. Therefore, FISH-negative test results with polysomy 17 (FISH ratio $<1.8$ or gene copy number $<4$ ) have to be validated by IHC. By application of the new expert consensus, a huge reduction in IHC false positive results and a reduction in FISH false negative test results can be assumed. To achieve this goal, the ASCO and CAP expert panel recommends i) validation of laboratory assays or modifications; ii) use of standardized operating procedures; iii) compliance with new testing criteria; iv) stringent laboratory accreditation standards; and v) proficiency testing and competency assessment [18].

A new technique to improve reproducibility of the test results and to increase response prediction is chromogenic in situ hybridization (CISH) which is currently in the process of FDA approval [22]. CISH is a colorimetric modification of the FISH assay that will probably replace FISH in the near future because of a higher accuracy of results.

\section{References}

1 Slamon DJ, Clark GM, Wong SG, et al.: Human breast cancer: correlation of relapse and survival with amplification of HER-2/neu oncogene. Science 1987;235:177-182.
Prenzel N, Fischer OM, Streit S, Hart S, Ullrich A: The epidermal growth factor receptor family as a central element for cellular signal transduction and diversification. Endocr Relat Cancer 2001;8:11-31.
3 King CR, Kraus MH, Aaronson SA: Amplification of a novel v-erbB-related gene in a human mammary carcinoma. Science 1985;229:974-976. 
4 Coussens L, Yang-Feng TL, Liao YC, et al.: Tyrosine kinase receptor with extensive homology to EGF receptor shares chromosomal localization with neu oncogene. Science 1985;230:1132-1139.

$\checkmark 5$ Schechter AL, Hung MC, Vaichanatan L, et al.: The neu gene: an erbB homologous gene distinct from and unlinked to the gene encoding for EGF receptor. Science 1985;229:976-978.

6 Vogel C, Cobleigh MA, Tripathy D, et al.: First line, single-agent herceptin (trastuzumab) in metastatic breast cancer: a preliminary report. Eur J Cancer 2001;37:S25-S29.

7 Slamon DJ, Leyland-Jones B, Shak S, et al.: Use of chemotherapy plus a monoclonal antibody against HER2 for metastatic breast cancer that overexpresses HER2. N Engl J Med 2001;344:783-792.

8 Marty M, Cognetti F Maraninchi D, et al.: Randomized phase II trial of the efficacy and safety of trastuzumab combined with docetaxel in patients with human epidermal growth factor receptor 2positive metastatic breast cancer administered as first-line therapy. J Clin Oncol 2005;23:4265-4274.

9 Tripathy D, Slamon DJ, Cobleigh M, et al.: Safety of treatment of metastatic breast cancer with trastuzumab beyond progression. J Clin Oncol 2004;22: 1063-1070.

10 Winer EP, Burstein HJ: New combinations with herceptin in metastatic breast cancer. Oncology 2001;61(suppl 2):50-57.
11 Fountzilas G, Razis E, Tsavdaridis D, et al.: Continuation of trastuzumab beyond progression is feasible and safe in patients with metastatic breast cancer. A retrospective analysis of 80 cases by the hellenic cooperative oncology group. Clin Breast Cancer 2003;4:120-125.

12 Von Minkwitz G, Vogel P, Schmidt M, et al.: Trastuzumab beyond progression in patients with HER-2 positive metastatic breast cancer - the TBP study (GBG 26/BIG 3-05). Breast Cancer Res Treat 2007;106(suppl 1):S185(abstr 4056).

13 Gelmon KA, Mackey J, Verma S, et al.: Use of trastuzumab beyond disease progression: observations from a retrospective review of case histories. Clin Breast Cancer 2004;5:52-58; discussion 59-62.

14 Burstein HJ, Harris LN, Marcom PK, et al.: Trastuzumab and vinorelbin as first-line therapy for HER2-overexpressing metastatic breast cancer: multicenter phase II trial with clinical outcomes, analysis of serum tumor markers as predictive factors, and cardiac surveillance algorithm. J Clin Oncol 2003;21:2889-2895.

15 Press MF, Sauter G, Bernstein L, et al.: Diagnostic evaluation of HER-2 as a molecular target: an assessment of accuracy and reproducibility of laboratory testing in large, prospective, randomized clinical trials. Clin Cancer Res 2005;11:6598-6607.

16 Perez EA, Suman VJ, Davidson NE, et al.: HER2 testing by local, central, and reference laboratories in specimens from the North Central Cancer Treatment Group N9831 intergroup adjuvant trial. J Clin Oncol 2006;24:3032-3038.
17 Miller DV, Jenkins RB, Lingle WL, et al.: Focal HER2/neu amplified clones partially account for discordance between immunohistochemistry and fluorescence in-situ hybridization results: data from NCCTG N9831 Intergroup Adjuvant Trial. Proc Am Soc Clin Oncol 2004;22: abstr 568

18 Wolff AC, Hammond MEH, Schwartz JN, et al. American Society of Clinical Oncology/College of American Pathologists guideline recommendations for human epidermal growth factor receptor 2 testing in breast cancer. J Clin Oncol 2007;25:118-145.

19 Ma Y, Lespagnard L, Durbecq V, et al.: Polysomy 17 in HER2/neu status elaboration in breast cancer: effect on daily practice. Clin Cancer Res 2005; 11:4393-4399.

20 Lal P, Salazar PA, Ladanyi M, et al.: Impact of polysomy 17 on HER-2/neu immunohistochemistry in breast carcinomas without HER-2/neu gene amplifiacation. J Mol Diagn 2003;5:155-159.

21 Hofmann M, Stoss O, Gaiser T, et al.: Central HER2 ICH and FISH analysis in a trastuzumab (Herceptin $\left.{ }^{\circledR}\right)$ phase II monotherapy study: assessment of test sensitivity and impact of chromosome 17 polysomy. J Clin Pathol 2008;61:89-94.

22 Hauser-Kronberger C, Dandachi N: Comparison of chromogenic in situ hybridization with other methodologies for HER2 status assessment in breast cancer. J Mol Histol 2004;35:647-653.

23 Smith IE: Efficacy and safety of Herceptin in women with metastatic breast cancer: results from pivotal clinical studies. Anticancer Drugs 2001;12 (suppl 4):S3-10. Review. 